\title{
O Teatro de máscaras de Platão
}

\author{
ANDRÉ MIRANDA DECOTELLI DA SILVA *
}

\section{* PUC-RIO}

Doutorando em Filosofia

Bolsista Capes
RESUMO O Sócrates de Platão é um filósofo misterioso. Com sua famosa ironia, ele se esquiva e dissimula suas intenções, se mostrando e se escondendo a cada passo. Desta feita, observamos que Platão, em seu teatro filosófico, mascara seu principal personagem, de forma que muitas são as facetas e imagens associadas a Sócrates. Nesse sentido, Sócrates, que representa também, possivelmente, a grande máscara platônica ao longo dos diálogos, é o mascarado maior de Platão. Nesse jogo de mascaramento, Platão pode preservar sua posição como autor, ao passo que cria um labirinto hermenêutico em torno da figura socrática, que, a princípio, seria o representante de suas ideias, como muitos interpretam. Com isso, Platão se mascara em Sócrates, que por sua vez é mascarado pelo próprio Platão ao longo dos diálogos. Em nosso artigo buscaremos destacar o jogo platônico de mascaramento, e, em especial, as máscaras dadas a Sócrates, contidas especificamente no Banquete, que são, a saber: a máscara de Dioniso, representada principalmente pela relação com os sátiros e silenos e a máscara de Eros, apresentada por Diotima, que é facilmente associada ao filósofo em questão.

PAlAVRAS-Chave Platão, Sócrates, Máscaras, Dioniso, Eros. 
Сомо bem se sabe ${ }^{1}$, Sócrates é um mistério. Sua real faceta está sempre sendo escamoteada por suas ações e discursos, que, por vezes parecem até ambíguos e contraditórios. Ele é estranho, inclassificável, átopos. Com sua famosa ironia, Sócrates se esquiva e dissimula suas intenções, se mostrando e se escondendo a cada passo, formando assim um labirinto hermenêutico para o leitor das obras de seu aluno mais famoso e como apontou Nietzsche, "tudo nele é exagerado, buffo (burlesco), caricatura; tudo é ao mesmo tempo oculto, de segundas intenções, subterrâneo”2. Desta feita, observamos que Platão em seu teatro filosófico, mascara seu principal personagem, de forma que muitas são as facetas e imagens associadas a Sócrates. Sobre o fato de intitularmos nosso artigo com o termo "teatro", fazemos como provocação e referência ao que ocorre no Banquete, uma espécie de drama satírico platônico e que se encerra com a questão posta por Sócrates de que é possível ao mesmo autor escrever tragédias e comédias. Seria o Banquete a proposta platônica de uma tragicomédia? Certamente essa questão tem seu lugar, mas não é o nosso intuito aqui desenvolvê-la. O que buscamos aqui ressaltar, como ponto de interseção entre o teatro e a filosofia platônica, é justamente o uso dramático de Platão de um expediente semelhante ao das máscaras do teatro.

Neste sucinto texto, buscaremos, então, destacar as máscaras socráticas contidas especificamente no diálogo Banquete, a saber, a máscara de Dioniso, representada principalmente pela relação com os sátiros e silenos e a máscara de Eros, apresentada por Diotima, que é também associada ao filósofo em questão. Cabe destacar, de início, que Platão mascara seu principal personagem por meio de outros também personagens (Diotima e Alcibíades), formando assim camadas de mediação narrativas. Aliás, no Banquete, diálogo extremamente rico, do ponto de vista literário e dramático, observamos que a sua própria composição inicial já é exposta por graus narrativos. Platão é o narrador maior, que por sua vez narra Apolodoro contando a alguém o que

1 É célebre a questão em torno da figura de Sócrates. A problemática em torno da real faceta histórica deste filósofo foi debatida em toda a história da filosofia. Para mais informações cf. MAGALHÃES-VILHENA, V. Estudos inéditos de filosofia antiga. Lisboa: F. Calouste Gulbenkian, 2005.

2 NIETZSCHE, 1976, p. 19 
teria contado outrora a Glauco, e tal acontecimento teria sido, por sua vez, contado antes para Apolodoro por Aristodemo. Tal rede de intermediações constitui uma tripla camada temporal, em que três pessoas teriam ouvido a história e a reproduzem, apontando para o que no diálogo será um tema caro, a saber, “a relação entre realidade e arte mimética, entre o fato e sua descrição ficcional e entre verdade e aparência.”3. Pode-se perceber também neste diálogo que seus personagens representam máscaras de Eros a partir de determinados nichos sociais, como, por exemplo, Erixímaco representa a medicina, Agatão a tragédia e Aristófanes a comédia. Sócrates é a máscara da filosofia, com sua estranheza e peculiaridade social. Como aponta Reale, o Banquete é um “complexo e belíssimo jogo de máscaras.”4

Ainda à guisa de introdução, Sócrates representa para muitos 5 a grande máscara platônica ao longo dos diálogos, e nesse sentido, Platão se mascararia em Sócrates, que por sua vez seria mascarado sob diversos outros arquétipos. Nesse jogo de mascaramento, Platão pode preservar sua posição como autor, ao passo que cria a urdidura dramática e um labirinto hermenêutico em torno da figura socrática. ${ }^{6}$

\section{MÁSCARA DE DIONISO}

No Banquete, Sócrates tem seu perfil descrito por Alcibíades num retrato que ficou fortemente marcado para a posteridade. Nele lemos:

Para elogiar Sócrates, meus senhores, vou recorrer a uma imagem que ele decerto tomará como caricatura; mas o fato é que minha comparação nada tem de risível; só visa à verdade. O que eu digo é que ele se parece com esses silenos

3 PINHEIRO, 2011, p. 34

4 REALE, 1997 apud MACEDO, 2003, p. 17.

5 Cf. HAVELOCK, 1983; NAILS, 2000; NIGHTINGALE, 1993; STRAUSS, 1963. Segundo Strauss, todos sabem que Platão fala pela boca, não do seu Protágoras, do seu Cálicles, do seu Ménon, do seu Hípias e do seu Trasímaco, mas do seu Sócrates, o seu estrangeiro eleata, o seu Timeu e o seu estrangeiro ateniense (1964). Já Vlastos argumenta que "À medida que Platão muda, a pessoa filosófica do seu Sócrates é forçada a mudar, absorvendo as novas convicções do escritor, argumentando em seu favor com o mesmo zelo com que o Sócrates dos diálogos anteriores tinha argumentado pela visão que o escritor tinha partilhado com o original desta figura anteriormente" (VLASTOS, 1991, p. 53)

6 Outra questão que contribuiu para a máscara platônica em Sócrates é o fato do filósofo autor dos diálogos quase não ser mencionado nos mesmos e nunca falar em seu nome próprio. Platão aparece nominalmente apenas três vezes, sendo duas na Apologia e uma no Fédon. 
expostos nas oficinas de escultores, (...) que, ao serem destampados, deixam ver no bojo várias estátuas da divindade. Digo mais: assemelhas-te também aos sátiros, ouve agora o seguinte: és ou não um zombador de marca (hybristés)??

Segundo o relato de Alcibíades, então, se pode também entender a relação de Sócrates com os silenos como uma aparência que esconde outra coisa, e nesse sentido, "a aparência quase monstruosa, feia, bufona, é apenas uma fachada e uma máscara" ${ }^{\text {. A }}$ fisionomia de Sócrates transmite uma mensagem, e ao que nos parece, a associação que Alcibíades estabelece aponta para o fato de que sua pessoa real se distingue daquilo que sua aparência denota. Ele afirma sobre o filósofo que “o que vocês veem não é senão o invólucro de que se rodeia, tal como o sileno esculpido. Mas uma vez aberto, imaginam, caros convivas, até que ponto seu exterior transborda temperança?" 9 Segundo as palavras do simposiasta, Sócrates não corresponde a seu exterior. Estaria aqui a personagem Alcibíades fazendo referência para a clássica distinção platônica entre aparência e essência? Não pretendemos aprofundar nessa questão, mas nos parece que ao longo de todo o diálogo este problema estará sendo apresentado, mesmo que de forma não explícita, uma vez que a conclusão socrática será de que o filósofo, através do eros, busca o belo em si, e não o apenas aparente. Retornemos à questão do discurso de Alcibíades.

Como vimos acima, no trecho do Banquete, será a partir da relação estabelecida por Alcibíades entre o filósofo e os sátiros e silenos, que a figura de Dioniso estará mais fortemente associada a de Sócrates. Segundo Hadot, “os silenos e sátiros eram na representação popular demônios híbridos, metade animais, metade humanos, que formavam o cortejo de Dioníso"10. Em uma primeira instância esta comparação se remeteria apenas aos aspectos físicos de Sócrates, que teria, assim como os sátiros, uma fisionomia estranha, com seus olhos salientes, nariz achatado e lábios grossos. ${ }^{11}$ No entanto, vemos que há em nosso filósofo semelhanças com o deus grego para além

7 Banquete, $215 \mathrm{a}-\mathrm{b}$

8 HADOT, 2012, p. 10.

9 Banquete, $216 \mathrm{~d}$

10 HADOT, 2012, p. 9

11 Muitas são as estátuas a partir do séc. V que corroboram a descrição platônica. Para mais cf. MARTENS (2013), HARTMAN (1927), CHARALABOPOULOS (2012). 
da questão física, contrariando, em parte, a sentença de Alcibíades. Dioniso pode ser assemelhado a Sócrates, pois conforme diz Vernant:

Seu papel não é confirmar e reforçar, sacralizando-a, a ordem humana e social. Dioniso questiona essa ordem; ele a faz despedaçar-se ao revelar, por sua presença, outro aspecto do sagrado, já não regular, estável e definido, mas estranho, inapreensível e desconcertante. Único deus grego dotado de poder de maya, de magia, ele está além de todas as formas, escapa a todas as definições, reveste todos os aspectos sem se deixar encerrar em nenhum. ${ }^{12}$

Como aponta Vernant, Dioniso é o deus grego que subverte a ordem social e humana, tal como o filósofo mestre de Platão ficou marcado ao longo da história. Dioniso é o deus grego que escapa a todas as definições, sendo portanto inclassificável, estranho e desconcertante, epitetos também geralmente dados a Sócrates. Segundo a tradição, ele seria um deus instável, errante, sem lugar de culto fixo, “um deus de lugar nenhum e de todo lugar"'13. Seria Dioniso átopos como Sócrates? Em contribuição a esta tese, podemos acrescentar a definição de Marcel Detienne: “Dioniso organiza o espaço em função de sua atividade ambulatória. É encontrado por toda parte, em nenhum lugar está em casa. Nem mesmo em um antro ou em um esconderijo na montanha, menos ainda à entrada de um santuário ou à luz de um templo urbano”. ${ }^{14}$ Vernant corrobora essa visão, ao sentenciar: “quanto a Dioniso, não é possível enquadrá-lo numa definição. Está ao mesmo tempo em todas e em nenhuma, presente e ausente ao mesmo tempo.”15. Ele é, então, o deus escorregadio ${ }^{16}$, que surge e desaparece subitamente, e “cuja força natural irrompe de repente e que permanece incompreensível, rebelde a qualquer classificação"17. Muitos são

12 VERNANT, 2006, p. 77

13 VERNANT, 2000, p. 144

14 DETIENNE, 1988, p. 14-15

15 VERNANT, 2000, p. 145

16 “como Dioniso está ligado ao elemento úmido, por ser uma divindade da vegetação, supunha-se que ele houvesse chegada a Atenas vindo do mar. É, por esse motivo, que integrava o cortejo uma embarcação, que deslizava sobre quatro rodas de uma carroça, puxada por dois sátiros. Na embarcação via-se o deus do êxtase, empunhando uma videira, ladeado por dois sátiros nus, tocando flauta. Um touro, destinado ao sacrifício, acompanhava o barulhento cortejo, cujos componentnes, provavelmente disfarçados de sátiros e usando máscara, cantavam e dançavam ao som da flauta." (BRANDÃO, 1996, p. 136)

17 DETIENNE, Op. Cit., p. 95 
os epítetos de Dioniso, é um deus de muitas faces. Por ser o deus do teatro, é, por conseguinte, também o deus das máscaras.

Dioniso, como o Sócrates de Alcibíades, é um enigma, um desconhecido. Sua capacidade de ao passo que se revela, também se ocultar, é bem semelhante à prática socrática da ironia, que se apresenta como de um jogo de simular e dissimular, de dizer a verdade e a mentira. Através de suas interrogações, Sócrates leva o seu ouvinte a reconhecer sua própria ignorância, colocando a vidas destes em questão. Aliás, colocar-se em questão seria justamente encontrar-se com a aporia, tão cara, e por que não, central na filosofia socrática. Nesse sentido, “a máscara, o prosopon, de Sócrates, desconcertante e inatingível, introduz uma perturbação na alma do leitor e ouvinte, e a conduz a uma tomada de consciência que pode ir até a conversão filosófica”18. E este processo pedagógico e psicagógico se inicia justamente no mascaramento socrático irônico, conforme observado em diversas obras platônicas, onde Sócrates simula sua inferioridade diante de seu interlocutor, momentaneamente superior, para enfim levá-lo à verdade. Será, aliás, a consciência socrática dos limites do saber humano uma experiência do desconhecido, do mistério, da privação, da pobreza, da penúria, tal como o Eros de Diotima, o “eterno vagabundo em busca da verdadeira beleza"19.

\section{MÁSCARA DE EROS}

Se, como vimos até aqui, Sócrates é mascarado pela figura de Dioniso, o mesmo se dá com outra entidade divina, o deus Eros. No Banquete, o discurso acerca de Eros promovido por Sócrates, retomando uma eventual conversa que este teria tido com Diotima, é marcado pela própria estranheza do referido deus. Segundo a sacerdotisa, Eros não é um deus, mas um dáimon, sendo um intermediário, metaxù, entre a sabedoria e a ignorância (202a), entre o feio e o mal (202b), entre o mortal e o imortal (202d) e entre os deuses e os mortais (202e). Essa é a sua natureza, sua physis tou daimonos. Ele é um intérprete, um hermeneûon entre os homens e deuses, permitindo que o "todo se ligue a si mesmo" (202e). Eros desejaria a todo custo o Belo de forma a saciar a falta do mesmo. Só amamos aquilo que não possuímos, e a busca amorosa

18 HADOT, 2012, p. 11

19 HADOT, Op. Cit., p. 26 
será sempre insatisfeita pela não aquisição do objeto amado. Ao mesmo tempo, o amante estará, por isso, constantemente em direção ao possuir o que lhe falta, assim como o filósofo, que ama o conhecimento que ainda não tem, mas que está sempre se lançando a ele. Sendo assim, Platão deixa evidente a relação que Sócrates tem com $\operatorname{Eros}^{2 \circ}$, e tal como este busca aquilo que lhe falta, Sócrates é o homem que busca a sabedoria que não tem. Tal como Eros, Sócrates vive descalço, é rude e sem beleza aparente. Assim como Sócrates, Eros é estranho, átopos, pois não é deus, nem homem, nem belo, nem feio, nem sábio, nem bom, nem mau. Sua característica mais marcante será o seu desejo. Sempre se lançando à frente, Eros é como Sócrates, amante da sabedoria, e que ama pois justamente não a tem. Desta feita, Eros e Sócrates são caçadores sedentos pelo saber e passam a vida inteira a filosofar.

Portanto, Sócrates é a personificação de Eros, e a filosofia apresenta uma natureza intrinsecamente erótica, cujos traços distintivos são representados por uma condição de falta, ou seja, de não autossuficiência, pela consciência deste déficit e pela tensão para a sua supressão. Diotima explicitará a relação entre Eros e o filósofo, afirmando que os que se dedicam à filosofia são intermediários entre a sabedoria e a ignorância, "como indubitavelmente sucede com o amor: pois se a sabedoria se conta entre as mais belas coisas e se o Amor é amor do belo, forçosamente terá de ser filósofo e, como filósofo, situar-se no meio termo entre sábio e ignorante" ${ }^{21}$. Num outro momento, é afirmado ainda a respeito de Eros que “os seus achados escapam-lhe continuamente das mãos, de tal sorte que nunca se encontra na indigência nem na riqueza: antes, num meio termo que é, de igual modo, entre a sabedoria e ignorância ${ }^{22}$. Assim como Eros, o filósofo é insaciável, pois jamais alcançará a plenitude em seus feitos. Isso dá a filosofia um caráter eminentemente de movimento, de tensão, de conflito, pois sua tarefa primaz será sempre a inquietude quanto ao seu objeto, uma vez que lhe escapa às mãos continuamente. O filósofo é como aquela clássica imagem do palhaço, que na medida em que conquista sua meta, logo a perde.

20 "Como ressalta Léon Robin, Sócrates é o verdadeiro filósofo e o perfeito erótico que completa e liga a ignorância e a sabedoria, a feiúra e a beleza, o ser e o não ser. Sócrates, como tipo ideal do filósofo, reconhece que não é perfeito nem acabado, mas aquele que tem em si a força dinâmica de quem assume as próprias carências e imperfeições, em uma contínua tensão para adquirir aquilo que não possui." (MACEDO, 2003, p.3,)

21 Banquete, $204 \mathrm{~b}$

22 Banquete, 203b 
O objetivo de Eros e do filósofo é o mesmo: a aquisição do belo. Para tanto, será preciso um esforço ascético e ascencional, e, por essa razão, o filósofo será um hybristés, uma vez que pela sua sophrosyne fugirá das expectativas convencionadas pelos status quo social, como quando inverte o coroamento a Agatão, ou quando inverta a posição de amante e amado com Alcibíades. Cabe ressaltar que aqui neste aspecto a hybris, se coaduna com as máscaras socráticas de Dioniso e de Eros. O primeiro é também o deus do excesso, da desmedida, e da mesma forma através da comparação com os sátiros e silenos, uma vez que estes são, em geral, tidos como hybristés. Já com relação a máscara de Eros, vemos em todo esforço erótico uma ascese do filósofo, que precisará romper as amarras do sensível como sendo o mais verdadeiro, a fim de que alcance a plenitude do objeto da filosofia, o belo em si, o inteligível. A hybris erótica se inscreve no âmbito sophrosysine, uma vez que ele inverte o procedimento padrão social, como quando alterna a posição de amante para amado na sua relação amorosa com Alcibíades. Mas a comparação aqui se dá por uma nova conceituação de hybris. Alcibíades acusará Sócrates de ser também um hybristés, mas diferente dos sátiros, que são desmedidos sexualmente, a hybris socrática se associa a sua sophroysine, e tem sua ilustração no episódio narrado por Alcibíades em que Sócrates teria o desprezado na cama. Aqui, fica claro o quanto Sócrates é estranho até mesmo em sua hybris, pois ao rejeitar o belo Alcibíades, ele inverte os padrões sociais convencionais, estabelecendo outro critério. Sócrates não tem o mesmo parâmetro de Alcibíades no que tange ao amor, uma vez que este último ama o particular, enquanto o primeiro busca o amor do universal, do belo-em-si, retratado do discurso de Diotima.

Alcibíades representa os valores temporais, que Sócrates parece querer inverter. A hybris de Sócrates nos leva diretamente à imagem clássica platônica da subordinação do convencional ao filosófico, do temporal ao eterno, do particular ao universal. Sendo assim, a hybris socrática se torna emblemática como um novo olhar moral, e precisaria ser associada à nova revaloração dos valores que Platão propõe, cuja relativa divergência em relação aos valores convencionais é ao mesmo tempo um prelúdio para o conhecimento, como uma consequência dele. 


\section{CONCLUSÃo}

Platão no Banquete parece, então, querer apontar para a dificuldade que há em se estabelecer a relação do filósofo com a cidade, sendo esta marcada pela estranheza que este proporciona. Tal esforço se observará em Alcibíades, e demonstra o seu estado de perplexidade diante de Sócrates, uma vez que o contato com ele produz em si uma aporía. Sócrates não tem paralelo possível, e para Alcibíades "nem entre os antigos nem entre os modernos é possível encontrar alguém a quem ele se assemelhe!” (221c). Se Aquiles tem Brásidas como semelhante, e Péricles tem Nestor e Antenor, Sócrates não tem quem se assemelhe, a não ser talvez os sátiros e silenos. No esforço em definir Sócrates, que é sem lugar, parece que Platão apenas encontra paralelos ao filósofo em arquétipos divinos como Dioniso e Eros, que também são, por sua vez, átopos, estranhos, como vimos. Talvez por essa razão será preciso ao filósofo, se podemos nos apoiar aqui em outro diálogo, ser um iniciado ${ }^{23}$ e adentrar nas portas do mistério, ou como sugere Sócrates no Fédon, “[...] como dizem os entendidos nos Mistérios, 'muitos são os portadores de tirso, mas poucos os bacantes': ora, estes últimos, quer-me parecer que não são outros senão os que se consagram, no verdadeiro sentido da palavra, à filosofia” ${ }^{24}$. O verdadeiro filósofo deve ser como as bacantes, como um iniciado nos mistérios, uma vez que a filosofia é o estar possuído por Eros. Esta concepção é fortemente marcada pela ideia presente no Banquete de que tal como Eros, que é um hábil feiticeiro, as palavras de Sócrates geram efeitos mais emotivos e profundos nos ouvintes que os efeitos do coribantes. ${ }^{25}$

Se nos cultos a Dionisio o delírio e a orgia tomavam os cultuantes, que ébrios de vinho, entravam em transe e experienciavam o desterro de sua vida cotidiana, desprendendo-se de si mesmos e mascarando-se, permitindo ao iniciado o ser outro - a

23 No Fédon, Platão fará Sócrates dizer: "Porque, como dizem os que tratam dos mistérios: ‘muitos são os portadores de tirso, porém pouquíssimos os verdadeiros inspirados”' (69c); a seguir Sócrates afirmará que os verdadeiros inspirados são aqueles que se ocupam da filosofia. A filosofia é como uma iniciação, que purifica a alma do homem. No Fedro também observamos o elogio a iniciação, quando, por exemplo, lemos que "Só atinge a perfeição o indivíduo que sabe valer-se da reminiscência e foi devidamente iniciado nos mistérios” (249c-d).

24 Fédon, 69c-d

25 "Ouvindo-te parece que fui drogado. Tu me enfeitiçastes tão bem que não sei mais o que penso" (Mênon, 8oa); "Mas a alma só pode ser curada por meio de discursos que agem como encantamentos” (Cármides, 156e) 
filosofia opera semelhante efeito. Se "Dioniso nos ensina ou nos obriga a tornar-nos o contrário daquilo que somos comumente" ${ }^{26}$, Sócrates, através da “magia" da filosofia também obriga seus interlocutores a uma transformação. Ele leva seus interlocutores a se tornarem o contrário do que eles são, tal como vemos sugerir Alcibíades ao afirmar que após ouvir Sócrates “era impossível continuar levando a vida que levava”27. Sócrates obriga, tal como Dioniso, a uma mudança:

Por obra e graça deste Mársias que aqui veem, muitas vezes cheguei a um tal estado que me parecia impossível continuar a levar a vida que levava! (...) Ainda hoje tenho a certeza absoluta de que, se quisesse dar-lhe ouvidos, não seria senhor de mim mesmo e me deixaria arrastar pelas mesmas emoções. É que ele obriga-me a reconhecer como, apesar das minhas imperfeições, esqueço o que devo a mim mesmo para me ocupar dos assuntos de Atenas! E assim, é à força que me escapo dele cerrando os meus ouvidos como se fugisse das Sereias... ${ }^{28}$

As máscaras socráticas de Dioniso e de Eros operam um efeito perturbador nos seus interlocutores. E este se dá pelo fato de que aos seus olhos e ouvidos, Sócrates é inclassificável, inominável, deslocado, ou como nas palavras de Diotima, nem feio, nem belo, nem bom nem mau. Sócrates é sempre pobre, está sempre na aporia, sempre à caminho, vagando pelas ruas de Atenas. Mas ele também é forte, e tal como Eros, é robusto; Sócrates é resistente ao frio e à fome, aos encantos sedutores e à embriaguez. Sócrates é um intermediário entre os deuses e os homens, que revela algo do mundo divino, um legítimo representante do belo, um amante em busca do que lhe falta, ou como segundo as palavras de Alcibíades: divino, demoníaco, espantoso (thaumastós) $^{29}$. Sócrates é misterioso como o é a esfera do divino, inacessível aos não iniciados, e com suas máscaras, se revela apenas aos que se deixam levar pela magia e a loucura da divina filosofia.

Platão, em seu teatro das máscaras, encerra o seu diálogo afirmando que Sócrates foi o único a permanecer acordado. E como de costume, fez o que fazia todos os dias, preparou-se para um dia idêntico a qualquer outro. Como no encerrar de uma peça

\footnotetext{
26 VERNANT, 2006, p. 80

27 Banquete, 215e-216a

28 Ibidem

29 Banquete, 219c
} 
teatral, saiu de cena, sendo convertido numa máscara de seu mais famoso discípulo, que assim o imortalizou.

\section{BIBLIOGRAFIA}

CHARALABOPOULOS, N. Platonic Drama and its Ancient Reception. Cambridge classical studies. Cambridge; New York: Cambridge University Press, 2012.

DETIENNE, M. Dioniso a céu aberto. Rio de Janeiro: Jorge Zahar Editor, 1988.

HADOT, P. Elogio de Sócrates. São Paulo, Loyola, 2012.

HARTMAN, A. “Silenos und Satyros”, in: Pauly's realenciclopadie der classischen Altertumswisenschaft. Leipzig, 1927.

HAVELOCK, E. A. (1983). “The Socratic Problem: Some Second Thoughts”, in Essays in Ancient Greek philosophy, Vol. 2. Albany: SUNY Press.

MACEDO, D. D. “O elogio do filósofo no Banquete de Platão” in: SÍNTESE - REV. DE FILOSOFIA, v. 30, N. 98, 2003, p. 407-415.

MAGALHÃES-VILHENA, V. Estudos inéditos de filosofia antiga. Lisboa: F. Calouste Gulbenkian, 2005 .

MARTENS, E. A questão de Sócrates: uma introdução. Trad. Vicente Sampaio.São Paulo: Odysseus Editora, 2013.

NAILS, Debra. “Mouthpiece, Schmouthpiece”, In: PRESS, G. (org.) Who speaks for Plato: studies in platonic anonimity. Lanham: Rowman and littlefield publishers, 2000, p. 15-26. NIETZSCHE, F. Crepúsculo dos ídolos. Trad. Edson Bini. São Paulo: Hemus, 1976

NIGHTINGALE, A. Genres in Dialogue: Plato and the Construction of Philosophy. Cambridge: Cambridge University Press, 1993.

PINHEIRO, Victor Sales. "Introdução ao Banquete de Platão” in: PLATÃO, Banquete. Trad. Carlos Alberto Nunes. Belém: Ed. UFPA, 2011.

PLATÃO, Apologia de Sócrates. Trad. Manuel de Oliveira Pulquério. Lisboa: Edições 70, 2009. 
, Banquete. Trad. M. Teresa Schiappa de Azevedo, Lisboa: Edições 70, 2015. , Cármides. Trad. Carlos Alberto Nunes, Belém: Ed. UFPA, 2015. , Fédon. Introdução, tradução e notas Maria Teresa Schiappa. Coimbra, 1983. , Mênon. Trad. Maura Iglésias. Rio de Janeiro: Ed. PUC-RIO; São Paulo: Ed. Loyola, 2001.

PUCHIVAILO, M. C., Uma ferida doce, um mal suave: a sabedoria dionisíaca no cuidado à saúde mental. Trabalho de Conclusão de Curso apresentado ao Programa de Pós-Graduação em Psicologia Analítica da Pontifícia Universidade Católica do Paraná, como requisito parcial à obtenção do título de Especialista. Curitiba, 2010.

REALE, G. Eros demone mediatore. Il gioco delle maschere nel Simposio di Platone. Milano, Rizzoli, 1997, In: MACEDO, D. D. “O elogio do filósofo no Banquete de Platão” in: SÍNTESE - REV. DE FILOSOFIA, v. 30, N. 98, 2003, p. 407-415.

STRAUSS, Leo. The city and man. Chicago and London: The University of Chicago, 1964. VERNANT, J-P. Mito e religião na Grécia antiga. São Paulo: WMF Martins Fontes, 2006 - O universo, os deuses, os homens / Jean-Pierre Vernant. Tradução de Rosa Freire d'Aguiar. São Paulo, Companhia das Letras, 2000.

VLASTOS, Gregory. Socrates. Ironist and moral philosopher. Cambridge: Cambridge University Press, 1991. 